\title{
Perfil de fisioterapeutas brasileiros que atuam em unidades de terapia intensiva
}

\author{
A profile of Brazilian physical therapists in intensive care units
}

\author{
Emilia Nozawa ${ }^{1}$, George J.V. Sarmento ${ }^{2}$, Joaquim M. Vega ${ }^{3}$, Dirceu Costa ${ }^{4}$, \\ José Euclides P. Silva ${ }^{5}$, Maria Ignez Z. Feltrim ${ }^{1}$
}

Estudo desenvolvido pela Assobrafir - Associação Brasileira de Fisioterapia Respiratória e Terapia Intensiva, São Paulo, SP, Brasil

1 Fisioterapeutas Dras. do Serviço de Fisioterapia do Instituto do Coração do Hospital das Clínicas da Faculdade de Medicina da Universidade de São Paulo, São Paulo, SP, Brasil

2 Fisioterapeuta do Hospital N.S. de Lourdes, São Paulo, SP, Brasil

3 Prof. Dr. do Depto. de Fisioterapia da Universidade Metodista de São Paulo, São Bernardo do Campo, SP, Brasil

4 Prof. Dr. do Programa de Pósgraduação em Fisioterapia da Universidade Metodista de Piracicaba, Piracicaba, SP, Brasil

5 Presidente do Conselho Federal de Fisioterapia e Terapia Ocupacional, Brasília, DF, Brasil

ENDEREÇO PARA

CORRESPONDÊNCIA

Dra. Emilia Nozawa

Av. Enéas de Carvalho Aguiar

442 andar

05403-000 São Paulo SP

e-mail: fis_emilia@incor.usp.br

Pesquisa elaborada pela Assobrafir com apoio do Conselho Federal de Fisioterapia e Terapia Ocupacional Uma versão deste estudo foi apresentada ao 17th European Respiratory Society Annual Congress, Estocolmo, Suécia, set 2007 .

APRESENTAÇÃO ago. 2007

ACEITO PARA PUBLICAÇÃO maio 2008
Resumo: Este estudo visou investigar o perfil dos fisioterapeutas que atuam nas unidades de terapia intensiva (UTIs) no Brasil, focalizando a direção do serviço, técnicas fisioterapêuticas empregadas e nível de autonomia em relação à ventilação mecânica invasiva e não-invasiva. Questionários foram enviados aos chefes dos serviços de fisioterapia de 1.192 hospitais registrados na Associação Médica de Terapia Intensiva, com retorno de 461 (39\%) UTIs. Em $88 \%$ destas, os serviços são chefiados por fisioterapeutas; em $78 \%$, compostos por até oito fisioterapeutas; $44,4 \%$ dos fisioterapeutas trabalham em regime de 30 horas semanais e 46,1\% têm contrato de trabalho. Há assistência fisioterapêutica durante 24 horas em 33,6\% das UTIs; $88 \%$ delas mantêm assistência nos finais de semana. Quanto às técnicas fisioterapêuticas, todos realizam mobilização, posicionamento e aspiração; 91,5\% atuam na ventilação não-invasiva, senḑo que $43 \%$ trabalham com total autonomia. Em relação à ventilação mecânica invasiva, $80 \%$ realizam extubação; 79,2\% realizam regulagem e desmame do ventilador; entretanto, só $22 \%$ têm total autonomia ( $78 \%$ necessitam de protocolo ou opinião da equipe médica). Os fisioterapeutas brasileiros atuam, em sua maioria, em instituições privadas e assistenciais, cujos serviços são chefiados por fisioterapeutas. Têm relativa autonomia quanto às técnicas fisioterapêuticas e o manuseio da ventilação mecânica não-invasiva mas, no caso da invasiva, atuam sob diretiva da equipe médica.

Descritores: Serviço hospitalar de fisioterapia/estatística \& dados numéricos; Unidades de terapia intensiva

ABSTRACT: The purpose of this study was to outline a profile of physical therapists who work in intensive care units (ICU) in Brazil, focusing on service management, techniques used, and the degree of therapists' autonomy regarding invasive and non-invasive mechanical ventilation. Questionnaires were sent to the heads of physical therapy (PT) services of 1,192 hospitals registered at the Brazilian Intensive Care Medicine Association and 461 (39\%) ICUs replied. In $88 \%$ of these, PT services are headed by physical therapists and up to eight therapists work in $78 \%$ of the ICUs. Therapists work 30 hours a week in $44.4 \%$ of the units; $46.1 \%$ are formally hired. PT 24-hour assistance is available in $32.8 \%$ of the ICUs and on weekends, in $88 \%$. Concerning PT techniques, all therapists perform mobilization, positioning, and aspiration; $91.5 \%$ play an active role in non-invasive ventilation, with $42.5 \%$ working with full autonomy. As to invasive mechanical ventilation, $80 \%$ perform extubation, $79.2 \%$ adjusting and weaning; however, only $22 \%$ have full autonomy (the others requiring physicians' protocol). Brazilian physical therapists work mostly in private institution ICUs, in services headed by physiotherapists, and have relative autonomy in handling $\mathrm{PT}$ techniques and non-invasive mechanical ventilation; as to invasive mechanical ventilation, most depend on protocols or discussions with a physician.

KEY words: Intensive care units; Physical therapy department, hospital/ statistics \& numerical data 


\section{INTRODUÇÃO}

Nas últimas décadas as unidades de terapia intensiva (UTIs) têm se tornado uma concentração não somente de pacientes críticos e de tecnologia avançada, mas também de uma equipe multiprofissional experiente com competências específicas ${ }^{1}$. O profissional fisioterapeuta, como integrante desta equipe, necessita cada vez mais de aprimoramento e educação especializada para fazer frente ao avanço dos cuidados intensivos. Em países desenvolvidos, a função do fisioterapeuta depende de muitos fatores, como a própria característica da inserção da Fisioterapia em cada país, a tradição, o nível do curso de graduação, treinamento e competência ${ }^{2}$. Embora existam poucos relatos na literatura sobre o perfil e a atuação profissional fisioterapêutica em UTIs, Norremberg et al. ${ }^{1}$ estudaram esse assunto em 17 países da Europa Ocidental e, apesar do número pequeno de respostas, constataram que havia diversidade quanto à função do fisioterapeuta e às técnicas empregadas. Outros estudos demonstraram que essas diferenças dependem também do número de profissionais fisioterapeutas exercendo funções ${ }^{2-4}$. No Brasil, embora os fisioterapeutas estejam cada vez mais presentes nas UTIs, sua atuação difere em cada instituição, não estando suas competências bem definidas. Diferentemente de outros profissionais, como médicos e enfermeiros que, tradicionalmente têm suas funções já consagradas devido à histórica existência ${ }^{5,6}$, a fisioterapia é uma profissão que só recentemente foi reconhecida no Brasil. Em nosso meio, a inserção do fisioterapeuta em UTI começou no final da década de 1970 e sua afirmação como integrante da equipe de assistência intensiva tem sido progressiva. Embora a aplicação das técnicas fisioterapêuticas se faça por profissionais da área e o processo educacional e de treinamento em terapia intensiva seja divulgado em todo o país, não se conhece a real inserção do fisioterapeuta nessa área de especialidade. Existem no Brasil mais de 1.500 unidades de terapia intensiva cadastradas na Associação de Me- dicina Intensiva Brasileira (Amib), com diferentes características e, possivelmente, com fisioterapeutas aí trabalhando. Porém, é difícil analisar as práticas assistenciais fisioterapêuticas e as responsabilidades assumidas por esse profissional sem dimensionar e caracterizar as condições da fisioterapia nas várias UTIs brasileiras.

Assim, justifica-se a realização deste estudo sobre o perfil do fisioterapeuta que atua nesse ambiente hospitalar para que, com base na realidade constatada, possam ser postas em prática perspectivas quanto à profissionalização e à educação na área da Fisioterapia em Terapia Intensiva. O objetivo deste estudo foi delinear o perfil dos fisioterapeutas que atuam nas unidades de terapia intensiva, focalizando aspectos administrativos, as técnicas fisioterapêuticas empregadas e o nível de autonomia em relação à ventilação mecânica invasiva e nãoinvasiva, bem como características das UTIs.

\section{METODOLOGIA}

Este estudo foi aprovado pelo Comitê de Ética em Pesquisa da Divisão Clínica do Hospital das Clínicas da Faculdade de Medicina da Universidade de São Paulo. Caracteriza-se como uma pesquisa de campo, prospectiva, transversal, com abordagem predominantemente quantitativa.

$\mathrm{O}$ instrumento utilizado para a coleta de dados constou de um questionário elaborado para este fim, contendo 20 questões fechadas versando sobre três temas principais: a) características da instituição, envolvendo dados demográficos, tipo e tamanho da instituição, áreas de atuação do fisioterapeuta dentro da instituição, categoria de pacientes por unidade, número de leitos e horário de atendimento fisioterapêutico da unidade; b) perfil do fisioterapeuta que atua nas UTIs, envolvendo formação do fisioterapeuta, vínculo empregatício, estrutura administrativa em que está inserido, jornada de trabalho, existência de programas de treinamento e educação continuada; c) tipo de técnicas fisioterapêuticas utilizadas, incluindo nível de decisão sobre o paciente em relação à ventilação mecânica invasiva e não-invasiva e procedimentos que o fisioterapeuta decide dentro da UTI. Além das 20 questões, foi acrescentada uma questão livre para que o questionado pudesse externar eventuais informações relevantes ao estudo. Para efeito de possíveis ajustes metodológicos, realizou-se um estudo piloto junto aos fisioterapeutas chefes de uma UTI de cada estado da federação, sendo um hospital público e outro privado, selecionados por randomização prévia.

Após o estudo piloto foram realizados ajustes no questionário e o mesmo foi encaminhado, via correio, aos chefes dos Serviços de Fisioterapia de todos os hospitais cadastrados na Amib, em envelope contendo: carta de apresentação com explicação dos objetivos do estudo e procedimentos adotados para a coleta de dados, Termo de Consentimento Livre e Esclarecido; o questionário e um envelope selado para envio das respostas. Os hospitais onde havia mais de uma UTI foram orientados a fazer cópias extras dos questionários. Passados 30 dias do envio, todos os hospitais foram contatados por telefone para confirmação de recebimento do material. Estipulou-se o prazo de dois meses (60 dias) para encerramento do recebimento das respostas.

As variáveis quantitativas estão apresentadas de forma descritiva, por meio de média e desvio padrão, levando-se em consideração a natureza e especificidade dos dados.

\section{RESULTADOS}

Dos questionários enviados a 1.192 hospitais, obtiveram-se respostas de 356 instituições $(29,9 \%)$ correspondendo a 461 UTIs (38,6\% dos questionários enviados). Essas UTIs estão alocadas em instituições privadas $(54,6 \%)$ e públicas da administração estadual $(16,7 \%)$, municipal $(10,7 \%)$ ou outra $(16,2 \%)$. Os números de leitos no hospital e nas UTIs são apresentados na Tabela 1. O maior número de respostas proveio de serviços que atuam junto a UTIs de pacientes adultos denominadas "geral" por admitirem casos de 
Tabela 1 Distribuição das UTIs (\%) segundo características e especialidade

\begin{tabular}{lc} 
Característica & $\%$ \\
\hline Números de leitos no hospital & \\
50 & 8,3 \\
$51-150$ & 30,1 \\
$151-300$ & 39,5 \\
$>300$ & 22,1 \\
\hline Especialidade da UTI & \\
Adulto geral & 64,9 \\
Adulto cirúrgico & 54,4 \\
Adulto neurológico & 29,5 \\
Pediátrica & 34,4 \\
Neonatal & 29,1 \\
Coronariana & 25,4 \\
Queimados & 8,2 \\
Oncológica & 2,8 \\
Outros & 11,1 \\
\hline Número de leitos na UTI & \\
$1-5$ & 7,2 \\
$6-10$ & 41,3 \\
$11-15$ & 22,3 \\
$16-20$ & 12,7 \\
$21-30$ & 11,6 \\
$>31$ & 5,0 \\
\hline
\end{tabular}

UTI = unidade de terapia intensiva

etiopatogenia variada $(64,5 \%)$, seguido de UTIs de caráter cirúrgico $(54,4 \%)$, de pediatria (34,4\%), neonatal $(29,1 \%)$ e coronariana $(25,4 \%)$.

De acordo com as informações recebidas, constata-se que a organização da atuação dos fisioterapeutas é exercida por uma estrutura administrativa denominada de Serviço $(70,9 \%)$ seguida de Setor $(21,2 \%)$, Unidade $(2,6 \%)$ ou outras $(5,4 \%)$. Para uniformizar a terminologia e com base nessa informação, tal estrutura é aqui referida como Serviço de Fisioterapia. Esta estrutura administrativa é liderada por fisioterapeuta em 91,9\% dos casos, embora outros profissionais exerçam o cargo de chefia, entre eles um médico $(5,6 \%)$, psicólogo $(1,1 \%)$ ou outros profissionais $(1,4 \%)$. O vínculo que os fisioterapeutas mantêm com os Serviços é trabalhista (contratado) em $46,1 \%$ dos casos; terceirizado, 29,9\%; profissional autônomo, 26,2\%; e em cooperativas, $3,7 \%$.

Em relação à força de trabalho no Serviço de Fisioterapia, verificou-se que $60 \%$ dos fisioterapeutas estão alocados nas UTIs e o restante atua possivelmente em unidades de internação geral e ambulatório. O número de fisioterapeutas que trabalham exclusivamente em UTI varia de acordo com a dimensão do hospital: em quase metade dos casos trabalham entre um e três fisioterapeutas, como mostra a Tabela 2; e em apenas 13 casos as UTIs comportavam mais de 30 profissionais.

As funções exercidas pelos fisioterapeutas que atuam nas UTIs são predominantemente $(52,4 \%)$ de assistência (Tabela 2). Para a maioria $(64,4 \%)$, a jornada de trabalho é de 30 horas semanais; a jornada de 20 horas e com plantões de 12 horas por 60 horas de descanso aparecem ocasionalmente. Os Serviços estão organizados a prestar assistência durante 24 horas somente em $1 / 3$ das UTIs, porém, a maioria $(88,8 \%)$ apresenta cobertura nos finais de semana (Tabela 2).

Os fisioterapeutas estão se aprimorando cada vez mais nessa área: verificou-se que $71 \%$ dos fisioterapeutas atuantes possuem curso de especialização em Fisioterapia Cardiorrespiratória ou em terapia intensiva; $67 \%$ responderam que seguiram programas de treinamento e desenvolvimento.

Tabela 2 Distribuição (\%) dos Serviços de Fisioterapia segundo características administrativas

\begin{tabular}{lccc}
\hline Funções exercidas & $\%$ & Atendimento nos finais de semana & $\%$ \\
Assistência & 52,4 & Sim & 88,8 \\
Assistência e ensino & 28,5 & Não & 7,2 \\
Assistência e pesquisa & 5,7 & Raramente & 4, \\
Assistência, ensino e pesquisa & 13,4 & & \\
\hline N. de Fts que compõem o Serviço & & N. de Fts exclusivos na UTI & \\
$1-3$ & 1,0 & 1 a 3 & 45,0 \\
$4-8$ & 29,9 & 4 a 8 & 33,6 \\
$6-10$ & 21,0 & 9 a 12 & 13,2 \\
$11-20$ & 20,3 & 13 a 20 & 5,9 \\
$21-30$ & 10,7 & 21 a 30 & 2,0 \\
$31-40$ & 10,2 & + de 30 & 0,3 \\
$>40$ & 6,9 & & \\
\hline Horário de atendimento & & Jornada de trabalho & \\
Raramente & 3,3 & 20 horas & 5,2 \\
$<12$ horas & 22,9 & 30 horas & 64,4 \\
12 horas & 34,2 & 40 horas & 17,6 \\
18 horas & 5,8 & 12 x 60 horas & 7,8 \\
24 horas & 33,6 & Mediante solicitação médica & 5,0 \\
\hline
\end{tabular}

$\mathrm{UTI}=$ unidade de terapia intensiva; Fts $=$ fisioterapeutas
A atuação fisioterapêutica caracteriza-se predominantemente pela aplicação de técnicas de remoção de secreção brônquica e de reexpansão pulmonar (99,3\%); a preocupação com a mobilização do paciente é tão importante quanto as técnicas de terapia respiratória $(91,5 \%)$. A utilização de dispositivos instrumentais como incentivador inspiratório, exercício com pressão positiva e flutter têm menor aplicação, como pode ser observado na Tabela 3. A tomada de decisão sobre os procedimentos fisioterapêuticos é de responsabilidade do profissional fisioterapeuta de forma preponderante em mais de 90\% dos casos. Quanto aos procedimentos de assistência ventilatória, cerca de $80 \%$ dos fisioterapeutas realizam os procedimentos de extubação, regulagem dos parâmetros ventilatórios e as etapas do desmame, como mostra a Tabela 3 .

Em relação à ventilação nãoinvasiva ( $\mathrm{VNI}$ ), 42,5\% deles têm total autonomia em sua indicação e aplicação e $49 \%$ realizam esse procedimento com base em protocolo discutido com a equipe médica; são raros os fisioterapeutas que não têm autonomia, como mostra o Gráfico 1. Quanto aos procedimentos de venti- 
Tabela 3 Distribuição dos fisioterapeutas (\%) segundo os procedimentos que realizam

\begin{tabular}{lc} 
Procedimento & $\%$ \\
\hline Remoção de secreção & 99,5 \\
Exercícios de expansão pulmonar & 99,3 \\
Aspiração orotraqueal & 99,0 \\
Posicionamento & 98,0 \\
Mobilização & 91,5 \\
Bag squeezing & 78,1 \\
Inspirometria de incentivo & 76,3 \\
Treinamento muscular respiratório & 76,3 \\
Exercícios com pressão positiva intermitente & 64,8 \\
Flutter & 53,1 \\
Medidas de pressão dos músculos respiratórios & 51,6 \\
Extubação & 80,0 \\
Ajuste do ventilador mecânico & 79,2 \\
Desmame da ventilação mecânica & 79,2 \\
Auxílio na intubação & 73,6 \\
Transporte intra-hospitalar & 37,2 \\
Auxílio na PCR & 66,9 \\
\hline PCR Parada cariorespiratoria
\end{tabular}

$\mathrm{PCR}=$ Parada cardiorrespiratória

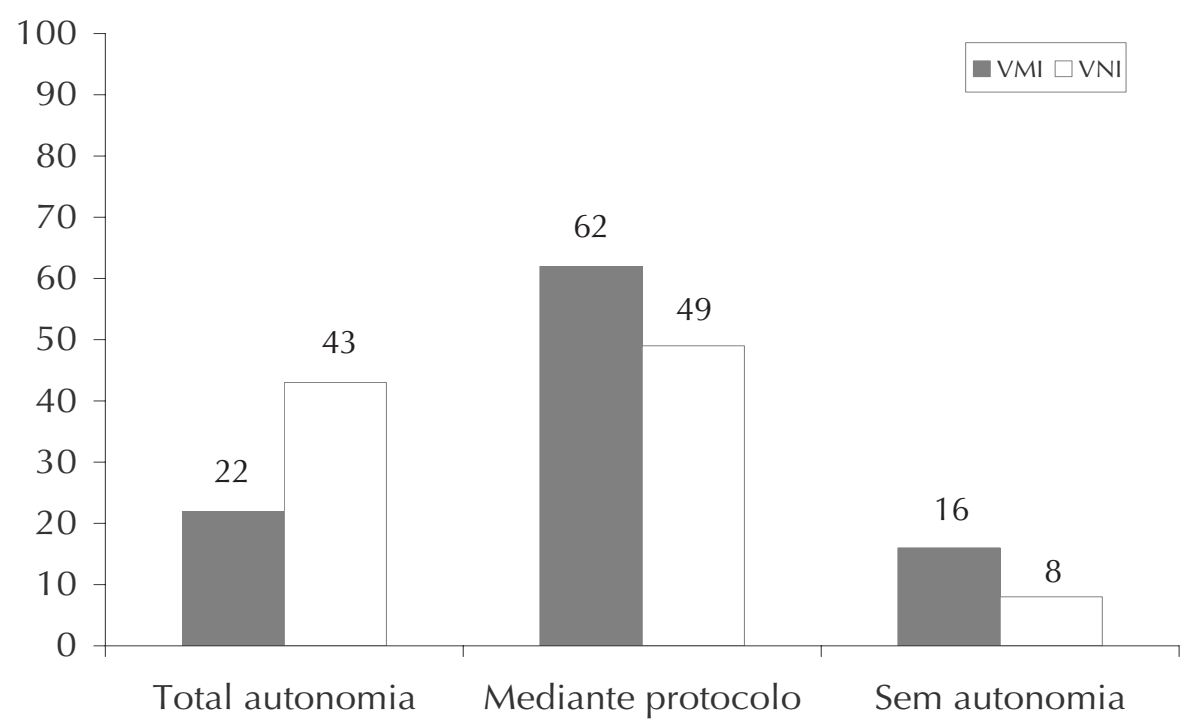

Gráfico 1 Distribuição percentual dos fisioterapeutas segundo o grau de autonomia em relação à ventilação mecânica invasiva (VMI) e à ventilação mecânica não-invasiva (VNI)

lação mecânica invasiva, somente $22 \%$ dos fisioterapeutas gozam de total autonomia sobre a condução do processo ventilatório e $62 \%$ necessitam, previamente, discutir com a equipe médica para determinar a conduta (Gráfico 1).

\section{DISCUSSÃO}

A atuação dos fisioterapeutas nas UTIs no Brasil vem aumentando de forma sistemática e gradual nas últi- instituições públicas. Esse fato pode ser atribuído a um maior número de hospitais privados, enquanto a melhor estruturação hierárquica do Serviço aí pode ter propiciado maior retorno dos questionários. Nas instituições públicas, os poucos fisioterapeutas atendem a uma demanda expressiva de pacientes sem a organização de uma equipe para a assistência exclusiva em UTI.

Os resultados mostram que os Serviços de Fisioterapia atendem principalmente pacientes adultos em vários tipos de terapia intensiva, o que revela a importância da atuação específica junto ao paciente crítico. Por outro lado, é expressiva a percentagem de atendimento na área de neonatologia e pediatria, que foi o segmento no qual a fisioterapia conquistou espaço mais recentemente, devido à complexidade e especificidade desses pacientes e/ou à resistência à presença do fisioterapeuta.

A atuação fisioterapêutica nas UTIs no Brasil ocorre no âmbito de uma estrutura administrativa denominada Serviço, tendo na liderança um fisioterapeuta. Esse dado justifica políticas de investimentos educacionais a serem destinados à gestão de processos, visando melhor preparo de lideranças administrativas de fisioterapeutas para gerir processos, resultados e capital intelectual.

Na dinâmica de trabalho das equipes destaca-se o percentual discreto $(33,6 \%)$ da assistência 24 horas, embora haja ampla cobertura diurna, incluindo finais de semana $(88,8 \%)$. Vários fatores podem justificar esse dado: a) na maioria das instituições, o reduzido número de fisioterapeutas vinculados (Tabela 2) pode não ser suficiente para a assistência ideal, particularmente na unidade de terapia intensiva, pois no atendimento 24 horas torna-se necessária a criação de três turnos (manhã, tarde, noite), o que equivale a, no mínimo, seis profissionais, mesmo para UTIs de pequeno porte; b) a jornada de trabalho de 30 horas reduz o total de horas vezes número de fisioterapeutas, levando necessariamente ao aumento no quadro de pessoal, o que pode onerar a 
folha de pagamento; c) a limitação do número de atendimentos por paciente, imposta pelos prestadores de saúde, independente das condições da fisioterapia, cria um sistema que enfoca atendimentos somente diurnos, deixando esses pacientes muitas vezes com um longo período sem intervenção.

Na caracterização da ação terapêutica junto aos pacientes críticos, há total concordância no emprego de técnicas de remoção de secreção brônquica e de reexpansão pulmonar realizada de forma manual. O dispositivo mecânico para tais fins vem secundariamente e pode ser devido ao custo adicional desses recursos. Este estudo não objetivou conhecer as técnicas mais empregadas, dada a grande variedade de técnicas existentes e a relação de seu uso com o treinamento recebido. Nos últimos anos foram desenvolvidas novas técnicas manuais ${ }^{8}$, porém ainda sem ampla divulgação e treinamento. O importante é que os fisioterapeutas brasileiros desenvolvem, em seus locais de trabalho, ações de remoção de secreções brônquicas, reexpansão pulmonar, posicionamento e mobilização. Essas são as principais ações necessárias aos pacientes críticos, conforme o Consenso Europeu de Fisioterapia de Pacientes Críticos da European Respiratory Society ${ }^{9}$.

O estudo mostra ainda que $71 \%$ dos fisioterapeutas em ação foram treinados por meio de cursos de especialização em fisioterapia cardiorrespiratória ou em terapia intensiva, vinculados à ação desenvolvida. Embora a dimensão geográfica do Brasil cause problemas quanto à uniformidade e acessibilidade aos programas de educação continuada, percebe-se claramente a preocupação de tornar mais específica a formação do fisioterapeuta para sua atuação em terapia inten- siva. Marques et al., em $1998^{10}$, realizaram uma pesquisa sobre o perfil e as expectativas dos fisioterapeutas do Complexo Hospital das Clinicas da Faculdade de Medicina da Universidade de São Paulo e verificaram que $98 \%$ dos fisioterapeutas demonstravam interesse em participar de eventos científicos, sugerindo que programas de atualização e reciclagem encontram um público constante.

A área concernente à ventilação mecânica invasiva, nos procedimentos de manuseio, regulagem e interrupção, merece atenção especial. Nota-se que essas práticas são exercidas amplamente por fisioterapeutas, seja nos pacientes intubados ou com suporte ventilatório nãoinvasivo. No entanto, a tomada de decisão que envolve iniciar, alterar e interromper a ventilação mecânica invasiva é realizada sob protocolo $(62 \%)$ ou sob ordem médica (16\%). As instituições estão cada vez mais adotando protocolos preestabelecidos pelos membros da equipe multiprofissional que atua nas UTIs, com base nas condições clínicas dos pacientes e nas recomendações adotadas mundialmente. Estudos randomizados demonstram que protocolos bem estruturados para descontinuar a ventilação mecânica realizados por fisioterapeutas adequadamente habilitados não requerem a presença do médico, podendo inclusive reduzir a duração da ventilação mecânica e melhorar os resultados $^{11-13}$. Norremberg et al. ${ }^{1}$ relatam que na Europa Ocidental o ajuste e desmame da ventilação mecânica realizado por fisioterapeutas difere de país para país: enquanto na Bélgica $57 \%$ dos fisioterapeutas realizam procedimentos de ventilação mecânica, na Suécia estes raramente são realizados. Portanto, é possível ampliar a participação do fisioterapeuta na ventilação mecânica invasiva, dependendo da organização e do grau de inter- relação das diferentes equipes que trabalham na UTI. Gestões que incentivem essa comunicação e intercâmbio de habilidades e competências devem ser propostas no âmbito local de trabalho, como também entre as instituições de representatividade dessas categorias.

O grau de autonomia do fisioterapeuta aumenta na VNI: no Brasil, 43,8\% dos fisioterapeutas têm total autonomia em relação à indicação e execução do procedimento. Estudos que mostram essa realidade enfatizam a necessidade de treinamento apropriado e experiência para se obter sucesso com a técnica ${ }^{14,15}$.

Os achados deste estudo mostram que os pacientes de terapia intensiva no Brasil recebem cuidados de fisioterapia de forma rotineira por fisioterapeutas, organizados e treinados para esse fim. A reflexão sobre esses resultados por parte de nossos órgãos e pelos próprios fisioterapeutas poderá gerar diretrizes e metas que propiciem recomendações de ações terapêuticas, normatização da estrutura administrativa, treinamentos técnicos e gerenciais, definições das relações de trabalho, efetividade no custo-saúde e remuneração qualificada, com resultados mais eficientes junto à população de pacientes críticos.

\section{CONCLUSÃO}

Pode-se concluir que o perfil dos fisioterapeutas brasileiros em unidades de terapia intensiva caracteriza-se por profissionais qualificados, que aplicam técnicas fisioterapêuticas especializadas com autonomia e estão envolvidos em ventilação mecânica invasiva e não-invasiva. A estrutura administrativa está relativamente bem organizada e promissora para o processo evolutivo profissional. 


\section{REFERENCIAS}

1 Norremberg $M$, Vincent JL [with the collaboration of the European Society of Intensive Care Medicine]. A profile of European intensive care unit physiotherapists. Intensive Care Med. 2000;26:988-94.

2 Stiller K. Physiotherapy in intensive care. Chest. 2000;118(6):1801-13.

3 Chaboyer W, Gass E, Foster M. Patterns of chest physiotherapy in Australian intensive care units. J Crit Care. 2004;19(3):145-51.

4 Jones AYM, Hutchinson RC, Oh TE. Chest physiotherapy practice in intensive care units in Australia, the UK and Hong Kong. Physiother Theory Pract. 1992;8:39-47.

5 Depasse B, Pauwels D, Somers Y, Vincent JL. A profile of European ICU nursing. Intensive Care Med. 1998;24:939-45.

6 Vincent JL, Suter P, Bihari D, Bruining H. Organization of intensive care units in Europe: lessons from the EPIC study. Intensive Care Med. 1997;23:1181-4.

7 Blot F, Melot C. Indications, timing and techniques of tracheosotomy in 152 French ICUs. Chest. 2005;127(4):1347-52.

8 Gosselink R. Physical therapy in adults with respiratory disorders: where are we? Rev Bras Fisioter. 2006;10(4):361-72.
9 Gosselink R, Bott J, Johnson M, Dean E, Nava S, Norremberg $M$, et al. Physiotherapy for adult patients with critical illness: recommendations of the European Respiratory Society and European Society of Intensive Care Medicine Task Force on Physiotherapy for critically III patients. Intensive Care Med. 2008;1027-37.

10 Marques AP, Cernigoy CHA, Juliani RCTP, Ayres VM, Carvalho EM, Takeda EH, et al. Perfil e expectativas dos fisioterapeutas do complexo Hospital das Clínicas da Faculdade de Medicina da Universidade de São Paulo. Rev Fisioter Univ São Paulo. 1997;4(2):92-100.

11 Ely W, Meade MO, Haponik EF, Kollef MH, Cook DJ, Guyatt $\mathrm{GH}$, et al. Mechanical ventilation weaning protocols driven by nonphysician healthcare professionals. Chest. 2001;120:454-63S.

12 Marelich GP, Murin S, Battistella F, Inciardi J, Vierra T, Roby M. Protocol weaning of mechanical ventilation in medical and surgical patients by respiratory care practitioners and nurses. Chest. 2000;118:459-67.

13 Wood G, MacLeod B, Moffatt S. Weaning from mechanical ventilation: physician-directed vs a respiratory therapist-directed protocol. Respir Care. 1995;40(3):219-23.

14 Moran FM, Bradley JM, Elborn JS, Piper AJ. Physiotherapy involvement in non-invasive ventilation hospital services: a British Isles survey. Int J Clin Pract. 2005;59(4):453-6.

15 Holland AE, Denehy L, Ntoumenopoulos G, Naugton MT, Wilson JW. Non-invasive ventilation assists chest physiotherapy in adults with acute exacerbations of cystic fibrosis. Thorax. 2003;58:880-4. 